\title{
IDENTIFICATION OF POTENT INHIBITORS OF COVID-19 MAIN PROTEASE ENZYME BY MOLECULAR DOCKING STUDY
}

\author{
Pooja Singh, Angkita Sharma, Shoma Paul Nandi*
}

Amity Institute of Biotechnology, Amity University, Noida-201313, Uttar Pradesh

\begin{abstract}
Within the span of a few months, the severe acute respiratory syndrome coronavirus, COVID19 (SARS-CoV-2), has proven to be a pandemic, affecting the world at an exponential rate. It is extremely pathogenic and causes communicable infection in humans. Viral infection causes difficulties in breathing, sore throat, cough, high fever, muscle pain, diarrhea, dyspnea, and may lead to death. Finding a proper drug and vaccines against this virus is the need of the hour. The RNA genome of COVID19 codes for the main protease $\mathbf{M}^{\text {pro }}$, which is required for viral multiplication. To identify possible antiviral drug(s), we performed molecular docking studies. Our screen identified ten biomolecules naturally present in Aspergillus flavus and Aspergillus oryzae fungi. These molecules include Aspirochlorine, Aflatoxin B1, Alpha-Cyclopiazonic acid, Sporogen, Asperfuran, Aspergillomarasmine A, Maltoryzine, Kojic acid, Aflatrem and Ethyl 3-nitropropionic acid, arranged in the descending order of their docking score. Aspirochlorine exhibited the docking score of $-7.18 \mathrm{Kcal} / \mathrm{mole}$, higher than presently used drug Chloroquine (-6.2930522 Kcal/mol) and out of ten ligands studied four has docking score higher than chloroquine. These natural bioactive compounds could be tested for their ability to inhibit viral growth in- vitro and in-vivo.
\end{abstract}

Keywords: COVID-19 virus, SARS-CoV-2, Aspirochlorine, Computer Aided-Drug Design technology, Docking study, Main Protease Enzyme (M $\left.{ }^{\text {pro }}\right)$, Aflatoxin B1, Alpha-Cyclopiazonic acid, Sporogen, Asperfuran, Aspergillomarasmine A, Maltoryzine, Kojic acid, Aflatrem

\section{Corresponding author}

Dr. Shoma Paul Nandi

Email ID: spaul@amity.edu 


\section{Introduction}

The year 2020 has brought along with itself a global tragedy in the form of a natural pandemic, named COVID-19. It has proven to be a highly pathogenic and transmittable viral infection causing the severe acute respiratory syndrome. It started in Wuhan, China, and has rapidly spread throughout the world. Coronavirus belongs to the family of Coronaviridae and order Nidovirales. The name corona comes from its crown-like spikes present in the outer membrane of the virus. It has a tiny size of $\sim 65-125 \mathrm{~mm}$ diameter with a nucleic material of single-stranded RNA of $26-32 \mathrm{kbs}$ in length [1]. The coronavirus family has the subgroups alpha $(\alpha)$, beta $(\beta)$, gamma $(\gamma)$ and delta $(\delta)$ coronavirus [2]. COVID-19, belongs to the beta subgroup and similar viruses can cause acute lung injury accompanied by acute respiratory distress syndrome. This leads to pulmonary failure and finally, death. There are three domains in the COVID-19 main protease (2019-nCoV $\mathrm{M}^{\text {pro }}$ ) that processes polypeptide with the help of a catalytic dyad. It consists of two amino acids histidine and cysteine, which act as catalytic residues. The active site of the protease is located between the two domains I and II. COVID-19 is a mutated form of SARS -CoV-1, and thus their proteases exhibit sequence similarity of about $96 \%$, only one amino acid, Ser46 varies between the two proteases in the area of the active site. Nevertheless, distinct variations are seen in the surface structure of the active site, mainly in the surrounding area of the loop that is centered on Asn142. Moreover, there is a distinct subcavity in COVID19 main protease as opposite to SARS-CoV-1 enzyme. As a result, the inhibitors of SARS protease are likely to present varied binding strategies for COVID-19 main protease. The similarities of COVID-19 main protease to other proteases of Middle-East Respiratory Syndrome coronavirus (MERS-CoV) or HIV are relatively low [3]. The main protease in COVID 19 participates in assemble and multiplication of the virus. Disrupting this virus's selfreplication machinery can be one of the ideal targets without causing any harm to the host. It has an active site for the inhibitors; compounds can interact at this active site of the enzyme and can interfere with the viral replication process at a different level. Due to interruption in viral transcription and the replication process, the virus cannot multiply itself (Fig.1).

The spikes are responsible for the attachment of the viruses on the surface and their subsequent entry into the host cells. One of the major causes behind the virus infecting multiple hosts is because of its loosely bound receptor-binding domains (RBD) [4]. Viruses like SARS-CoV and MERS-CoV attack the exopeptidases, while other viruses recognize carbohydrates and aminopeptidases for their entry into the host cells. SARS-coronavirus use angiotensinconverting enzyme 2 (ACE2) as the primary receptor $[4,5,6,7,8,9]$. 
Thus, developing spike glycoprotein targeted drugs against SAR coronaviruses is an appropriate decision [10]. So far no specific drug against COVID 19 has been approved by the US Food and Drug Administration Agency.

The world at the moment is in a dire need for new drugs against the wrath of COVID-19, one that combines efficiency with minimal side effects, which also has to be inexpensive and readily available. The conventional methods of drug discovery are laborious, time-consuming, and also very costly. An alternative approach to combat this problem is the use of computerassisted structure-based drug design (SBDD) or the computer-aided drug design (CADD) In the current study, we used structure-based computational modeling of ligand-receptor interactions. The present study deals with the in-silico study of various fungal secondary metabolites as potential drugs against COVID-19 protease enzyme $\mathrm{M}^{\text {pro }}$ as the receptor. Our study identified aspirochlorine as a potential candidate drug for inhibiting the main protease of COVID19 followed by nine other compounds

\section{Method and material}

The in- silico study was carried out by using Schrodinger Maestro, including protein preparation (protein preparation wizard), ligand preparation (LigPrep), grid generation, and receptor-ligand docking (GlideSP docking). The Centos Linux operating system was used for the computational study.

\section{Protein and chemical compounds}

Ten fungal secondary metabolites (ligands) were downloaded from the NCBI (http://www.ncbi.nlm.nih.gov/pccompound). Fungal chemical compounds were taken from literature [11]. The X-ray crystal structure of COVID-19 main protease $\mathrm{M}^{\text {pro }}$, PDB ID: 5R80 having $1.93 \AA$ resolution was retrieved from the Protein Data Bank (PDB) [12].

\section{Protein Preparation}

The $\mathrm{M}^{\text {pro }}$ protein was prepared for a docking study by using in Schrodinger 2019-2 Maestro software. Protein preparation wizard has three steps, preprocess, optimization, and minimization. During the preprocessing step, water molecules were deleted, and hydrogens were added from the protein. Ramachandran plot was obtained after the protein preparation process.

\section{Ligand preparation}


All ten ligand compounds were prepared using LigPrep, which can produce low energy isomer of the ligand in optimization by using the OPLS_2005 force field. By the ligprep, molecule format was changed .sdf to .out.maegz format, and ligand structure was converted 2D to a 3D structure. The ligand was prepared by adding hydrogen atoms, removing unwanted molecules, generating ionization states at $\mathrm{pH}$, tautomers, geometric characteristics, and low-energy ring conformations. The ligfilter process was used for eliminating molecules which had molecular weight more than 1000, based on presence and absence of functional group. The obtained .out.maegz file was used for the docking analysis.

\section{Grid generation}

The OPLS_2005 force field was used for generating Grid on protein receptors [13]. During grid generation, Van der Waals radii of protein $(1.00 \AA)$ were adjusted with a 0.25 atomic charge. The grid generation process was provided square block at the active site of the protein for the accurate binding score with thermodynamic optimal energy. Protein- grid out file (glidegrid_name.maegz) was used for the docking study of natural compounds or ligand with $\mathbf{M}^{\text {pro }}$ protein.

\section{Molecular docking}

Schrodinger 2019-2 version was used to predict the binding affinity, ligand competence, and inhibitory candidate to the protein [14] by performing rigid, flexible docking. Molecular docking was conducted with fungal secondary metabolites by using the Glide SP (standard precision) module of Schrodinger Maestro software (Schrödinger Release 2019-2). In the present study, we prepared ten ligands (fungal chemical compounds produced as secondary metabolites) obtained from the fungi Aspergillus flavus and A. oryzae, which were docked with generated Grid of receptor protein PDB ID: 5R80. The optimal ligand selection for the receptor was done based on the docking score.

\section{Results}

The $\mathrm{M}^{\text {pro }}$ is a $\sim 306$ amino acid long main protease, the crystal structure with a resolution of $1.93 \AA$ has been elucidated (11). The $\mathrm{M}^{\text {pro }}$ enzyme is best target for inhibiting the SARS CoV. $[15,16,17]$. These proteases break the spikes and further establish by penetration $[18,19]$. 


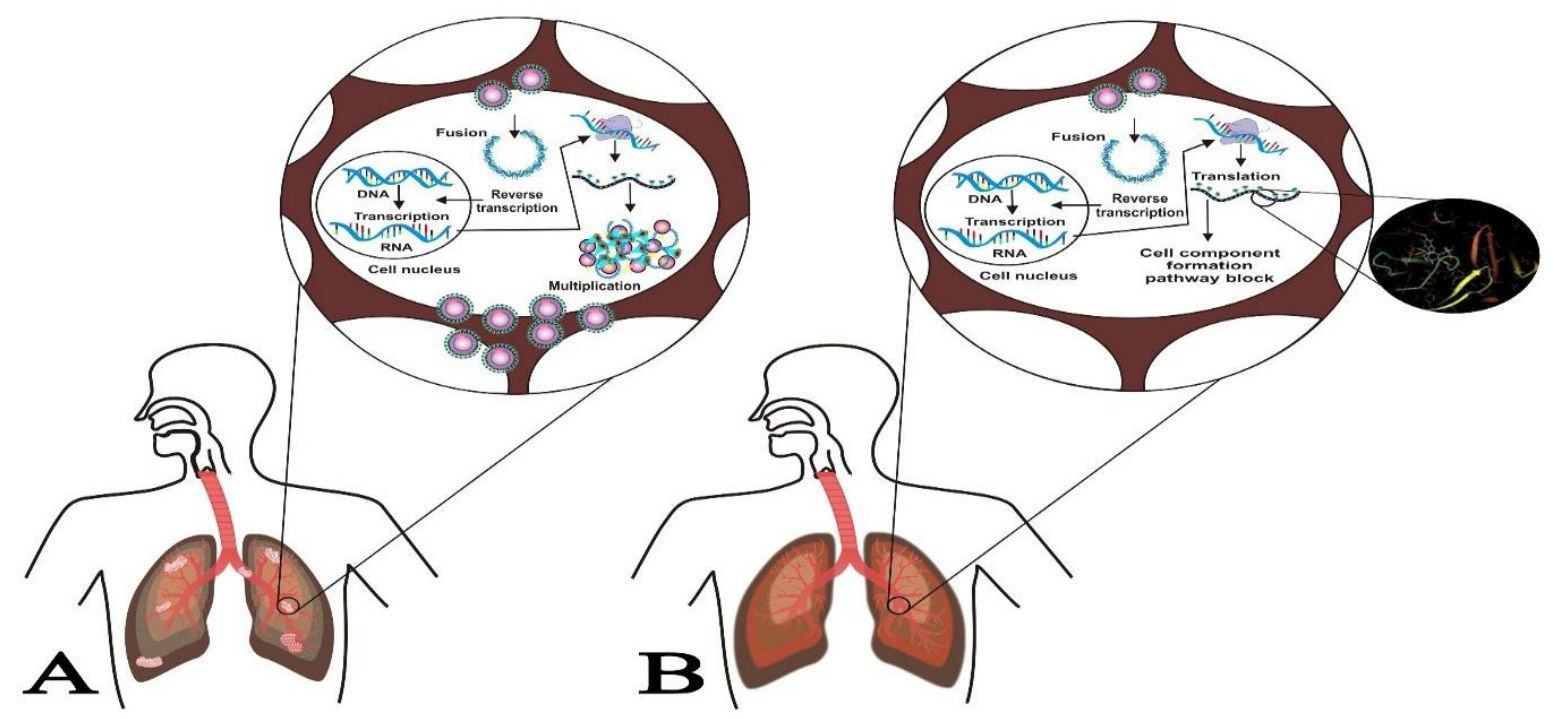

Fig1: A. Viral spread into the lungs and its replication; B.Viral infection cycle and role of main protease $\mathrm{M}^{\text {pro }}$ inhibitor (aspirochlorine) in viral replication.

This study was taken to identify possible compounds that can bind to the $\mathrm{M}^{\text {pro }}$, which may be used as a potential drug for COVID 19. Among the different compounds tested, we found ten fungal-derived molecules that can bind with the $\mathrm{M}^{\text {pro }}$ with a docking score of-7.18 to -4.13 (Table 1).

We observed out of all the compounds studied, aspirochlorine had a higher docking score and the best binding affinity with main protease $\mathrm{M}^{\text {pro }}$ than the other ligands. Ligands used in this study are downloaded from NCBI, and they are secondary metabolites of fungus A. flavus and A. oryzae, which can be synthesized in submerged liquid media in aseptic conditions in a controlled environment in the fermenter [20]. Aspirochlorine (CID_13945563) belongs to the gleotoxin family and reported to have antibacterial [21] and antifungal activity [22]. Aspirochlorine had had a significantly higher docking score $(-7.18 \mathrm{kcal} / \mathrm{mol})$ than others. The other compounds (Table 1) also show a significant strength of interaction with the $\mathrm{M}^{\text {pro }}$ protein. There are few reports on the binding energy of COVID-19 protease enzyme, with a natural compound like Terpenoides [23]. Following the global outbreak of COVID 19, chloroquine is being used as a drug along with several antiviral molecules [24, 25]. The mode of action of chloroquine on COVID-19 is still not known. Our compounds, including aspirochlorine likely to inhibit the process of viral replication and translation and may have much significant impact on controlling the viral load in infected individuals. Moreover, the docking score of chloroquine $(-6.2930522 \mathrm{Kcal} / \mathrm{mol})$ is lesser than aspirochlorine $(-7.18)$ and three other ligands Aflatoxin B1 (-6.74), $\alpha$-cyclopiazonic acid (-6.61), Sporogen AO1 (-6.23) enlisted in Table -1. 
Table 1: Ten fungal inhibitors of COVID-19 protease enzyme $\mathbf{M}^{\text {pro }}$

\begin{tabular}{|c|c|c|c|c|c|c|c|}
\hline $\begin{array}{l}\text { SI } \\
\text { No }\end{array}$ & $\begin{array}{l}\text { Compound } \\
\text { Structure }\end{array}$ & $\begin{array}{l}\text { Name } \\
\text { (Form } \\
\text { ula) }\end{array}$ & CID & $\begin{array}{l}\text { Molec } \\
\text { ular } \\
\text { Weig } \\
\text { ht } \\
\text { (g/mo } \\
\text { l) }\end{array}$ & $\begin{array}{l}\text { Docki } \\
\text { ng } \\
\text { Score } \\
\text { (kcal/ } \\
\text { mol) }\end{array}$ & $\begin{array}{l}\text { Interaction } \\
\text { Residues }\end{array}$ & 3D Structure \\
\hline 1 & & $\begin{array}{l}\text { Aspiroc } \\
\text { hlorine } \\
\left(\mathrm{C}_{12} \mathrm{H}_{9}\right. \\
\mathrm{ClN}_{2} \mathrm{O}_{5} \\
\left.\mathrm{~S}_{2}\right)\end{array}$ & $\begin{array}{l}1394 \\
5563\end{array}$ & 360.8 & -7.18 & CYS145, & \\
\hline 2 & & $\begin{array}{l}\text { Aflatox } \\
\text { in } \mathrm{B} 1 \\
\left(\mathrm{C}_{17} \mathrm{H}_{12}\right. \\
\left.\mathrm{O}_{8}\right)\end{array}$ & $\begin{array}{l}1869 \\
07\end{array}$ & $\begin{array}{l}312.2 \\
7\end{array}$ & -6.74 & GLU166 & \\
\hline 3 & & $\begin{array}{l}\alpha- \\
\text { cyclopi } \\
\text { azonic } \\
\text { acid } \\
\left(\mathrm{C}_{20} \mathrm{H}_{20}\right. \\
\left.\mathrm{N}_{2} \mathrm{O}_{3}\right)\end{array}$ & $\begin{array}{l}5467 \\
5761\end{array}$ & 336.4 & -6.61 & GLU166 & \\
\hline
\end{tabular}




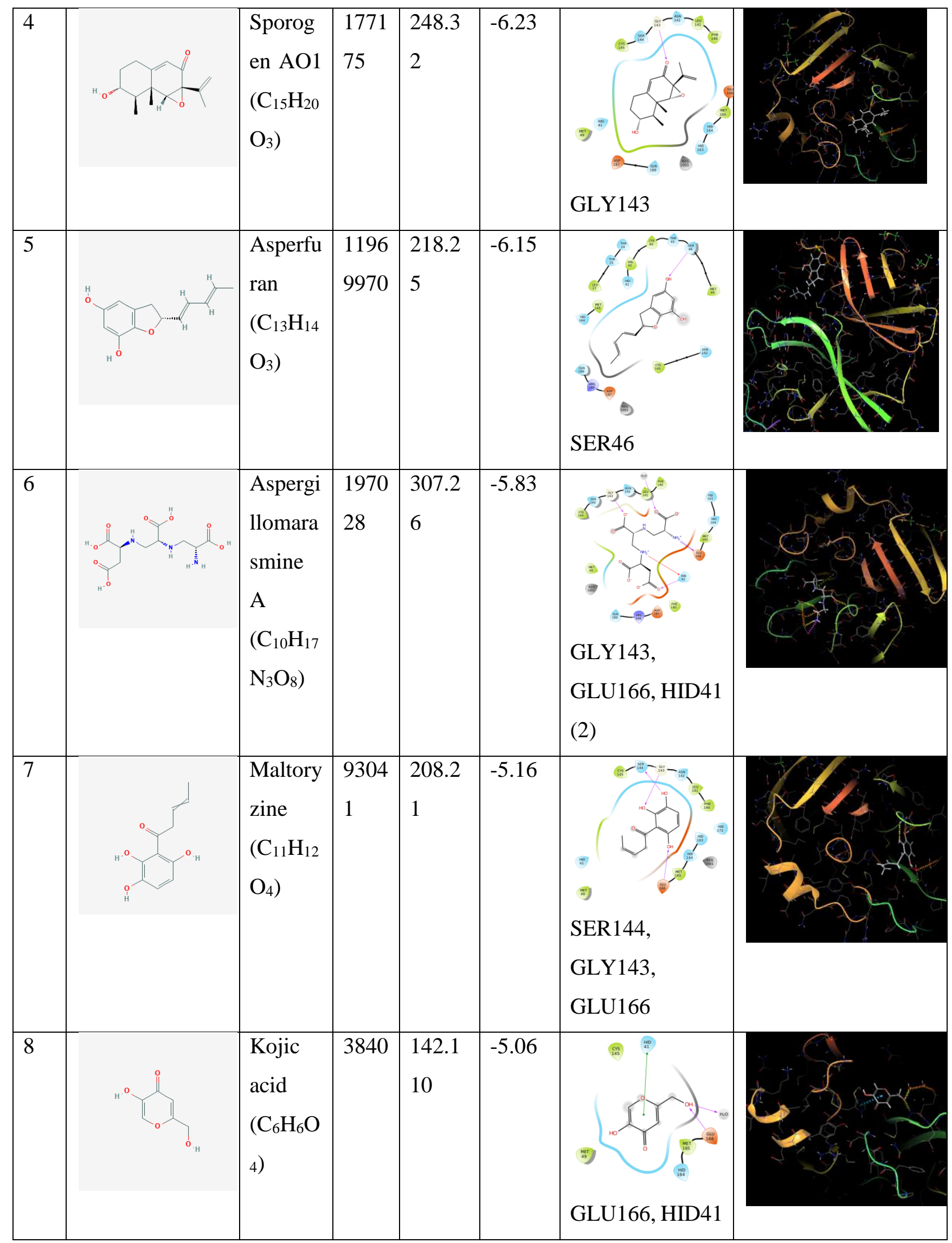




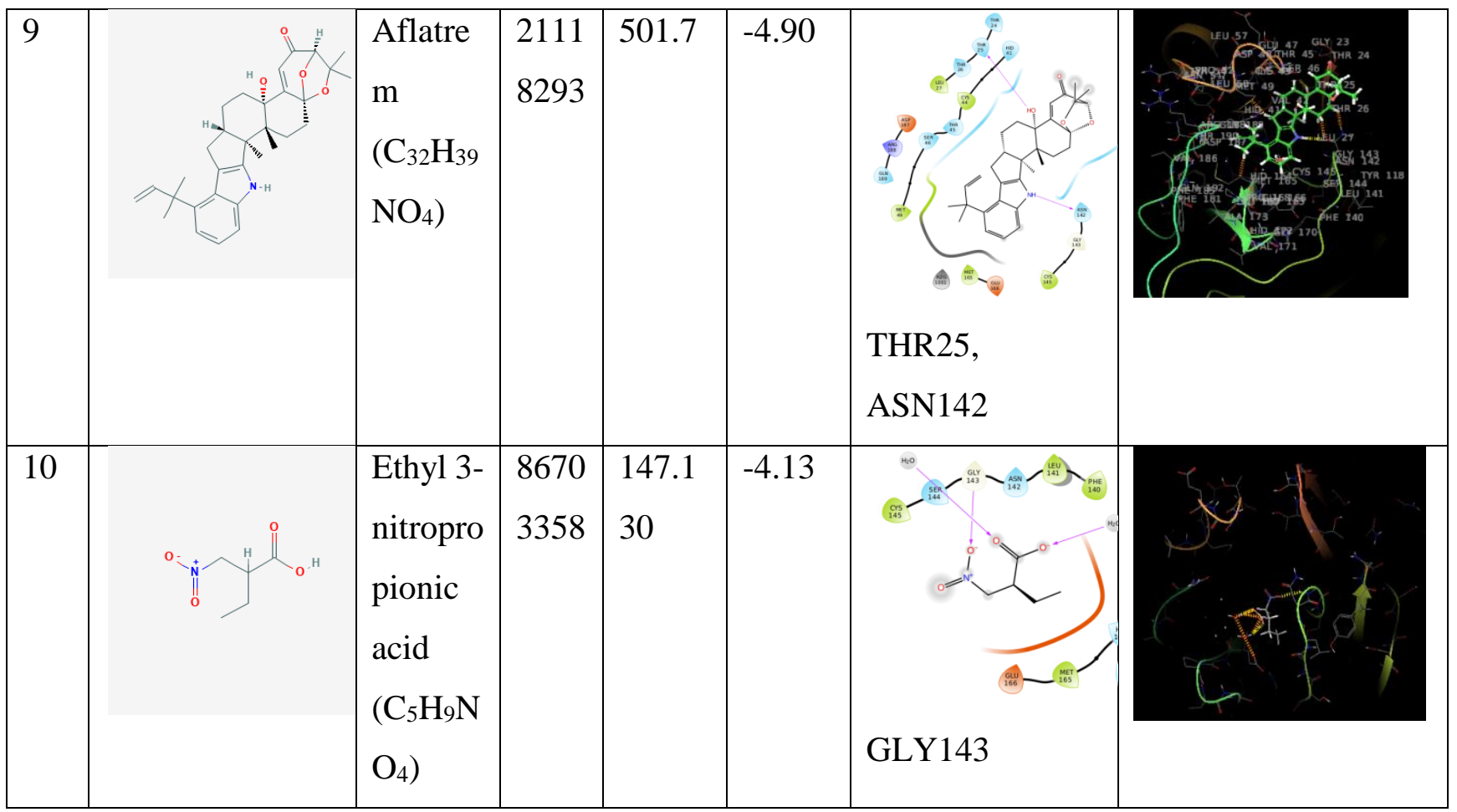

*Source: A. oryzae-1, 4,5,6,7,8; A. flavus -2,3, 8,9,10

\section{Conclusions}

Our screen identified ten bioactive compounds of Aspergillus sps with the potentialities to bind the main protease enzyme $\left(\mathrm{M}^{\mathrm{pro}}\right)$ of the COVID-19 virus. Aspirochlorine showed the best docking score compared to the other ligands against COVID-19 main protease enzyme. The different ligands, followed by Aspirochlorine, are Aflatoxin B1, Alpha-Cyclopiazonic acid, Sporogen, Asperfuran, Aspergillomarasmine A, Maltoryzine, Kojic acid, Aflatrem, and Ethyl 3-nitropropionic acid. These molecules may have antiviral activities against COVID19.

\section{Conflict of interest}

The authors declare that there are no conflicts of interest.

\section{Acknowledgement}

Pooja Singh is grateful to CSIR-UGC NET-JRF for fellowship. The authors are grateful to the Mr. Harinder Singh for making figures for this paper.

\section{References}

1. Anthony, R.F. and Stanley P., 2015. Coronavirus: An overview of their replication and pathogenesis. Methods Mol. Biol. 1283, 1-23. doi: 10.1007/978-1-4939-2438-7_1

2. Adnan Shereen, M., Khan, S., Kazmi, A., Bashir, N., and Siddique, R., 2020. COVID19 infection: origin, transmission, and characteristics of human coronaviruses, Journal of Advanced Research. doi: https://doi.org/10.1016/j.jare.2020.03.005. 
3. Gao, K., Nguyen, D. D., Wang, R., and Wei, G.W., 2020. Machine intelligence design of 2019- nCoV drugs. bioRxiv. 2020.01.30.927889. doi: https://doi.org/10.1101/2020.01.30.927889.

4. Raj, V.S., Mou, H., Smits, S.L., Dekkers, D.H., Muller, M.A., and Dijkman, R., et al. 2013. Dipeptidylpeptidase 4 is a functional receptor for the emerging human coronavirus-EMC. Nature. 495(7440), 251-254. doi: 10.1038/nature12005.

5. Zhong, N., Zheng, B., Li, Y., Poon, L., Xie, Z., and Chan, K., et al. 2003. Epidemiology and cause of severeacute respiratory syndrome (SARS) in Guangdong, People's Republic of China, in February, 2003.The Lancet. 362(9393), 1353-1358. DOI:10.1016/s0140-6736(03)14630-2

6. Wang, N., Shi, X., Jiang, L., Zhang, S., Wang, D., and Tong, P., et al. 2013. Structure of MERS-CoV spikereceptor-binding domain complexed with human receptor DPP4. Cell Res. 23(8), 986-993. doi.org/10.1038/CR.2013.92.

7. Cui, J., Li, F., and Shi, Z.L., 2019. Origin and evolution of pathogenic coronaviruses. Nat. reviews Microbiol. 17(3), 181-92. doi: 10.1038/s41579-018-0118-9.

8. Lai, C.C., Shih, T.P., Ko, W.C., Tang, H.J., and Hsueh, P.R., Severe acute respiratory syndromecoronavirus 2 (SARS-CoV-2) and corona virus disease-2019 (COVID-19): the epidemic and the challenges. Int J Antimicrob Agents. 55(3), 105924. doi: 10.1016/j.ijantimicag.2020.105924.

9. Wang, C., Horby, P.W., Hayden, F.G., and Gao. G.F., 2020. A novel coronavirus outbreak of global health concern. The Lancet. 395(10223), 470-473. DOI:https://doi.org/10.1016/S0140-6736(20)30185-9

10. Nagata, N., Iwata, N., Hasegawa, H., Fukushi, S., Yokoyama, M., and Harashima, A., et al., 2007. Participation of both host and virus factors in induction of severe acute respiratory syndrome (SARS) in F344 rats infected with SARS coronavirus. J. virol. 81(4), 1848-57. DOI:10.1128/JVI.01967-06

11. Christian, A., Devaux, J.M.R., Philippe, C., and Didier, R., 2020. New insight on the antiviral effects of chloroquine against coronavirus: what to expect for COVID-19? , Int. J. Antimicrob. Agents. doi: http://doi.org.1016/j.ijantimicag.2020.105938

12. Fearon, D., Powell, A.J., Douangamath, A., Owen, C.D., Wild, C. Krojer, T., Lukacik, P., Strain-Damerell, C.M., Walsh, M.A., and von Delft, F., 2020. Crystal Structure of COVID-19 main protease in complex with Z18197050. DOI: $10.2210 / p d b 5 R 80 / p d b$ 
13. Jorgensen, W.L., Maxwell, D.S., and Rives, J.T., 1996. Development and testing of the OPLS All-atom force field on conformational energetic and properties of organic liquids. Am. Chem. Soc. 118, 11225-11236. https://doi.org/10.1021/ja9621760

14. Meng, X.Y., Zhang, H.X., and Mezei, M., et al., 2011. Molecular docking: a powerful approach for structure-based drug discovery. Curr. Comput. Aid. Drug Des. 7, 146157. DOI:10.2174/157340911795677602

15. Zhang, L., Lin, D., Sun, X., Curth, U., Drosten, C., Sauerhering, C., Becker, S., Rox, K. and Hilgenfeld, R., 2020.Crystal structure of SARS-CoV-2 main protease provides a basis for design of improved $\alpha$-ketoamide inhibitors. Science. DOI: 10.1126/science.abb3405

16. Xue, X., Yu, H., Yang, H., Xue, F., Wu, Z., Shen, W., Li, J., Zhou, Z., Ding, Y., Zhao, Q., Zhang, X.C., Liao, M., Bartlam, M., and Rao, Z., 2008. Structures of two coronavirus main proteases: implications for substrate binding and antiviral drug design. J. Virol. 82, 2515-2527. DOI: 10.1128/JVI.02114-07

17. Li, Y., Zhang, J., Wang, N., Li, H., Shi, Y., Guo, G., Liu, K., Zeng, H., and Zou, Q., 2020. Therapeutic Drugs Targeting 2019-nCoV Main Protease by High-Throughput Screening. bioRxiv. https://doi.org/10.1101/2020.01.28.922922

18. Glowacka, I., Bertram, S., Müller, M.A., Allen, P., Soilleux, E., and Pfefferle, S., et al., 2011. Evidence that TMPRSS2 activates the severe acute respiratory syndrome coronavirus spike protein for membrane fusion and reduces viral control by the humoral immune response. J. virol. 85(9), 4122-34. DOI: 10.1128/JVI.02232-10

19. Bertram, S., Glowacka, I., Muller, M.A., Lavender, H., Gnirss, K., and Nehlmeier, I., et al., 2011. Cleavage and activation of the severe acute respiratory syndrome coronavirus spike protein by human airway trypsin-like protease. J. virol. 85(24), 13363-72. DOI: 10.1128/JVI.05300-11

20. Son, S.Y., Sunmin Lee, S., Digar, Singh, D., Na-Rae Lee, N-R., Lee, D-Y and Lee, CH., 2018. Comprehensive Secondary Metabolite Profiling Toward Delineating the Solid and Submerged-State Fermentation of Aspergillus oryzae KCCM 12698. 2018 Front. Microbiol. 9,1-12. doi: 10.3389/fmicb.2018.01076.

21. Sakata, K., Toshiaki, K., Akira, S., Nobutaka,·T., and Gakuzo, T., 1983. Isolation of Aspirochlorine (=Antibiotic A30641) as a True Antimicrobial Constituent of the Antibiotic, Oryzachlorin, from Aspergillus oryzae. Agric. Biol. Chem. 47 (11), 2673 2674. https://doi.org/10.1080/00021369.1983.10866014 
22. Klausmeyer, P., McCloud, T.G., Tucker, K.D., Cardellina, J.H., and Shoemaker, R.H., 2005. Aspirochlorine class compounds from Aspergillus flavus inhibit azole-resistant Candida albicans. J. Nat. Prod. 68, 1300-1302. DOI:10.1021/np050141k

23. Neda, S., 2020. Molecular Docking Study of Novel COVID-19 Protease with Low Risk Terpenoides Compounds of Plants. ChemRxiv. Preprint. doi:https://doi.org/10.26434/chemrxiv.11935722.v1.

24. Wang, M., Cao, R., Zhang, L., Yang, X., Liu, J., and Xu, M., et al., 2020. Remdesivir and chloroquine effectively inhibit the recently emerged novel coronavirus (2019nCoV) in vitro. Cell Research. 1-3. https://doi.org/10.1038/s41422-020-0282-0.

25. Wang, B.X., and Fish, E.N., 2019.Global virus outbreaks: Interferons as 1st responders. Semin Immunol. 43,101300. doi:10.1016/j.smim.2019.101300 